\title{
Quem é o empreendedor brasileiro? Discursos em concorrência
}

\author{
Who is the Brazilian entrepreneur? Competing discourses
}

\author{
Maria Cecília de Souza-e-Silva \\ Pontifícia Universidade Católica de São Paulo/CNPq \\ Vivian Cristina Rio Stella \\ Pontifícia Universidade Católica de São Paulo \\ Centro Universitário Padre Anchieta - Jundiaí - São Paulo
}

\begin{abstract}
Resumo: O tema do empreendedorismo tem norteado políticas e ações nas esferas governamentais, entidades de classe e na academia, constituindo e consolidando discursos sobre, com e para os empreendedores, que reverberam na mídia segmentada certo "tom" característico da imagem discursiva de tais enunciadores. Colocando em diálogo duas perspectivas, a discursiva e a ergológica, pergunta-se: qual é o ethos do jovem empreendedor construído pela revista PME Exame? O que dizem seus enunciadores? O que silenciam? E, por outro lado, o que diz um jovem empreendedor, quando levado a falar sobre sua atividade de trabalho? Os enunciados constituídos pela PME estão pautados pela didaticidade e prescrição, enquanto os do empreendedor trazem reflexões que deixam entrever o "debate de normas" e "debate de valores" que perpassam seu cotidiano. Ambos constroem identidades enunciativas que estão em relação de concorrência em sentido amplo, isto é, sua delimitação recíproca não passa por um confronto aberto.
\end{abstract}

Palavras-chave: Perspectiva discursiva; Abordagem ergológica; Empreendedorismo; Identidades enunciativas; Debate de normas/debate de valores

\begin{abstract}
The theme of entrepreneurship has guided policies and actions in governmental spheres, professional associations and in Academia, constituting and consolidating discourses about, with and to entrepreneurs, which reverberate, in the segmented media, a certain "tone" that is characteristic of the discursive image of such enunciators. Contrasting two perspectives, the discursive and the ergological, we ask: what is the ethos of the young entrepreneur constructed by the Brazilian magazine PME Exame? What do its enunciators say? What don't they say? And, on the other hand, what does a young entrepreneur say when he is asked about his work activity? The enunciations constituted by $P M E$ are marked by didacticism and prescription, while those of the entrepreneur bring reflections that hint at the "debate of norms" and "debate of values" that pervade his daily routine. Both construct enunciative identities that are in a competition relation in the broad sense, that is, their reciprocal delimitation does not undergo an open confrontation.
\end{abstract}

Keywords: Discursive perspective; Ergological approach; Entrepreneurship; Enunciative identities; Debate of norms/debate of values

\section{Introdução}

Nos últimos quinze anos, há um crescente e significativo interesse pelo tema do empreendedorismo, que, cada vez mais, norteia políticas, ações e discursos nas esferas governamentais, nas entidades de classe, nas instituições de apoio, na mídia e na própria academia (COSTA; BARROS; MARTINS, 2012).
Esse crescente interesse é acompanhado também pelo aumento significativo no Brasil do número de empreendedores e aspirantes a empreendedores, que criam seus negócios por oportunidade ou por necessidade. Segundo a pesquisa do Global Entrepreneurship Monitor (GEM) "Empreendedorismo no Brasil 2013", o sonho de abrir a própria empresa já superou o desejo de os indivíduos terem uma carreira "tradicional" (43,5\% 
contra $24,7 \%$ ). Dentre as faixas etárias analisadas pelo GEM, destacam-se os empreendedores com idades entre 18 e 24 anos, entre 25 e 34 anos e entre 35 e 44 anos, que correspondem, respectivamente, a 14,2\%, 19,2\% e $18,7 \%$ dos empreendedores iniciais brasileiros, isto é, que estão abrindo seu primeiro negócio (GEM, 2013).

Em tal contexto, derivam, constituem-se e se consolidam discursos sobre o empreendedorismo e os empreendedores, reverberando, na mídia segmentada, o "tom" característico da imagem discursiva, isto é, do ethos dos enunciadores. Esse tom, entendido como uma certa vocalidade específica, se apoia sobre uma dupla figura do enunciador, a de um "caráter" e a de uma "corporalidade" estreitamente associados, cujo grau de precisão varia segundo os textos (MAINGUENEAU, 2013, p. 108). A figura do enunciador caracteriza-se "psicologicamente", isto é, é afetada por disposições mentais, um conjunto de traços psicológicos que são o correlato dos afetos que o modo de enunciação engendra e também por uma compleição "corporal", isto é, um conjunto de determinações físicas, uma maneira de se vestir e se movimentar no espaço social, uma disciplina tácita do corpo, apreendida através de um comportamento. "O destinatário a identifica apoiando-se num conjunto difuso de representações sociais, avaliadas positiva ou negativamente, em estereótipos que a enunciação contribui para confrontar ou transformar [...]" (MAINGUENEAU, 2008a, p. 18)

Pergunta-se, então, qual é o ethos do jovem empreendedor construído pela revista PME Exame? O que dizem seus enunciadores? O que eles silenciam? Nossa hipótese é a de que o "debate de normas" e as "dramáticas do uso de si" (SCHWARTZ, 2010, 2011) são silenciados, a favor de discursos pautados pela didaticidade e prescrição do que é ou deve ser empreender, construindo, assim, uma identidade do empreendedor que passa a ser aceita sem releituras ou debates.

E por que a revista PME Exame? Pelo lugar institucional que a revista ocupa no cenário brasileiro: primeiro, por ser uma publicação direcionada a empreendedores e vinculada à marca Exame, publicação mensal da Editora Abril, com mais de 40 anos de existência e grande respeitabilidade entre seus leitores e no campo midiático mais amplo; segundo, pela sua representatividade em termos de circulação: em nove anos de existência, a tiragem média é de 65.107 , o número de assinatura média de 38.991 e a circulação líquida média de 44.457 (fonte: IVC jan.-fev./2015), com um total de 116.289 leitores, segundo a Projeção Brasil de Leitores consolidado 2014'; finalmente, pela autodesignação $O$

\footnotetext{
Para efeito de comparação, a Revista Exame, com 40 anos de mercado, tem assinatura média de 130.048 e tiragem media de 189.162 , com circulação líquida de 150.513 (fonte: IVC jan-mar/2015). O total de leitores é de 726.465, segundo Projeção Brasil de Leitores consolidado 2014.
}

Manual do Empreendedor Brasileiro, atrelada ao título da publicação e estampada com destaque na capa da edição abril de 2015 (Fig. 1).

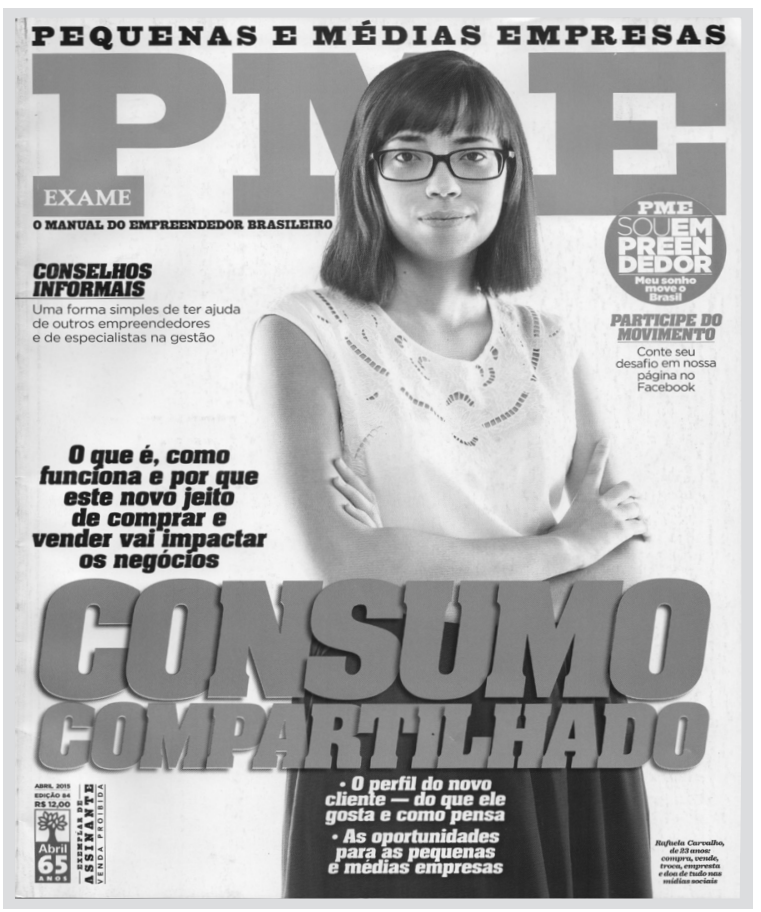

Figura 1. capa da edição de abril/2015

Tal designação, acompanhada pelos Conselhos Informais, caracterizados como simples, nas próprias palavras da revista, e, ainda, pelo "bottom" PME Sou Empreendedor - Meu sonho move o Brasil, indicam o propósito da revista: integrar os empreendedores, promover troca de experiência e conhecimento e construir histórias de sucesso. Esses elementos norteiam, por exemplo, a seção Quero saber, em que os leitores podem sugerir temas sobre os quais têm dúvida, "Conte seu desabafo em nossa página no Facebook", os quais depois de selecionados se apresentam em duas partes, ambas sobre o mesmo assunto - Quero Saber/O que Aprendi. No mês de maio, Endomarketing - Comunicação. A primeira parte responde à pergunta formulada no Facebook - apresenta-se como um pedido de orientação: Como melhorar a Comunicação? E a segunda, como resultado de orientação: $O$ que aprendi relata o resultado favorável obtido depois dos conselhos da revista.

\section{Abordagens sobre o empreendedorismo}

O fenômeno do empreendedorismo, considerado uma nova forma de "tecnologia gerencial" para prover 
alternativas de empregabilidade, pode ser explicado pela nova realidade por que passa o mercado de trabalho, com o declínio de formas clássicas de atuação profissional. Estamos vivendo, segundo alguns autores, o início de um capitalismo empreendedor, em que os empreendedores estão:

[...] eliminando barreiras comerciais, e culturais, encurtando distâncias, globalizando e renovando os conceitos econômicos, criando novas relações de trabalho e novos empregos, quebrando paradigmas e gerando riqueza para a sociedade. (DORNELAS, 2008, p. 6)

As diferentes inovações - seja a introdução de um novo bem, de nova característica em bem já existente ou de um novo método de produção, seja, ainda, a abertura de novo mercado, a descoberta de novas fontes de suprimento ou o desenvolvimento de novas formas de organização - são potencializadoras de perturbações que direcionam as economias e as sociedades ao desenvolvimento. $\mathrm{O}$ empreendedor é, então, o agente que inicia tais mudanças, alterando o sistema em equilíbrio ao identificar novas oportunidades.

As várias concepções de empreendedorismo, nas teorias e pesquisas sobre o tema, podem ser agrupadas, segundo Costa, Barros e Carvalho (2011), autores que discutem apropriações da ideia de empreendedorismo ao longo da história, em três abordagens: uma, derivada da perspectiva de base behaviorista ou comportamental; outra, ancorada em estudos sobre habilidades e competências; uma terceira, pautada por bases econômicas.

A abordagem de base behaviorista procura definir os perfis das personalidades do empreendedor e compreender seu comportamento. A segunda relaciona as habilidades e competências empreendedoras ao espaço organizacional, contemplando várias correntes teóricas e discutindo temas como: (a) empreendedorismo como fomento tecnológico; (b) empreendedorismo como gestão (difusão da prática da gestão empreendedora); e (c) empreendedorismo como estratégia de desenvolvimento local integrado e sustentável. A terceira abordagem, alinhada à perspectiva de base econômica, concentra-se nas relações entre o tema e as ideias de inovação, risco calculado e desenvolvimento, realçando o caráter inovador, as novas oportunidades de investimento, de produto ou de negócios e a criação de novas empresas.

Tais abordagens, embora com suas especificidades, convergem para o mesmo ponto:

o atual processo de valorização, celebração e exaltação do empreendedor e do empreendedorismo privilegia um modelo específico de desenvolvimento econômico e social pautado pelo capitalismo de mercado, assumido como natural, ideal e exemplar.
A partir dessa ótica, para que uma sociedade possa potenciar todos os supostos benefícios provenientes de um mercado livre capitalista, necessita do espírito empreendedor gerador de inovação e de riquezas. (COSTA; BARROS; CARVALHO, 2011, p. 183)

Nesse contexto sócio-histórico, o empreendedorismo passa a ser considerado como fator fundamental para o desenvolvimento econômico, "potenciando lucros por intermédio de uma 'visão' ou um 'espírito' muitas vezes mais pessoal do que coletivo" (COSTA; BARROS; CARVALHO, 2011, p. 183). Os empreendedores, ainda segundo os autores, se constituem como os indivíduos que impulsionam a máquina capitalista, com a função social de identificar oportunidades e convertê-las em valores econômicos.

\section{Quem é o empreendedor "Abaixo dos 40"?}

A naturalização do princípio de que o profissional contemporâneo é uma unidade econômica autônoma, que provê novos bens de consumo, métodos inovadores de produção, caracteriza o discurso que circula na seção delimitada para análise, Abaixo dos 40, focada em relatos de empreendedores de sucesso, cuja faixa etária é destacada pelo GEM.

A página é sempre composta pelo título da seção, posicionado na parte superior; uma foto de corpo inteiro do empreendedor em destaque em um cenário que representa seu negócio; informações gerais sobre a empresa diagramadas como uma ficha técnica; um subtítulo que qualifica o empreendedor e um breve relato sobre sua trajetória/de sua empresa, conforme as edições de abril, maio e junho de 2015, respectivamente, Figuras 2,3 e 4 .

Os enunciadores que se apresentam no paratexto identificam-se pelo nome e sobrenome, um deles francês, outro mineiro, não por acaso desenvolvendo suas atividades prioritariamente em São Paulo, considerada o centro de trabalho, produção e eficiência; pela idade, entre 18 e 29 anos, portanto abaixo dos 30; pelas empresas que criaram, todas voltadas para a área tecnológica, respectivamente, site e aplicativo para contratação de serviços de entrega, serviço online de intermediação de pagamento e plataforma de distribuição de vídeos online. Os aportes de investidores e de fundos nacionais e estrangeiros e as receitas obtidas, entre 2 e 8 milhões de reais, indicam métricas de sucesso e compõem a imagem de jovialidade do empreendedor.

Tanto o título quanto os subtítulos da seção constituem as chamadas frases "sem texto" ou aforizações (MAINGUENEAU, 2013). O que é uma frase sem texto? A problemática de tais frases remete à noção de 


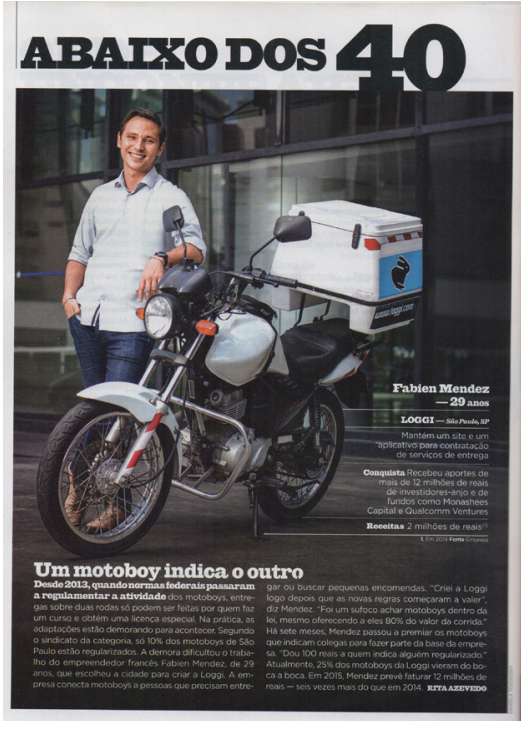

Figura 2. Edição abril/2015

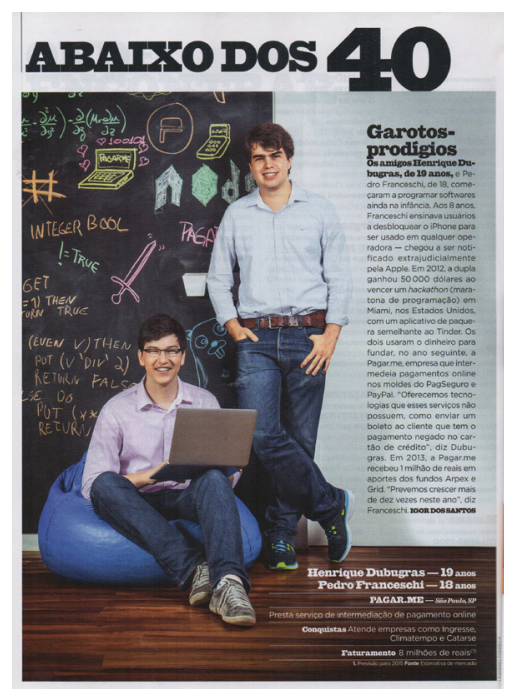

Figura 3. Edição maio/2015

Figura 4. Edição junho/2015

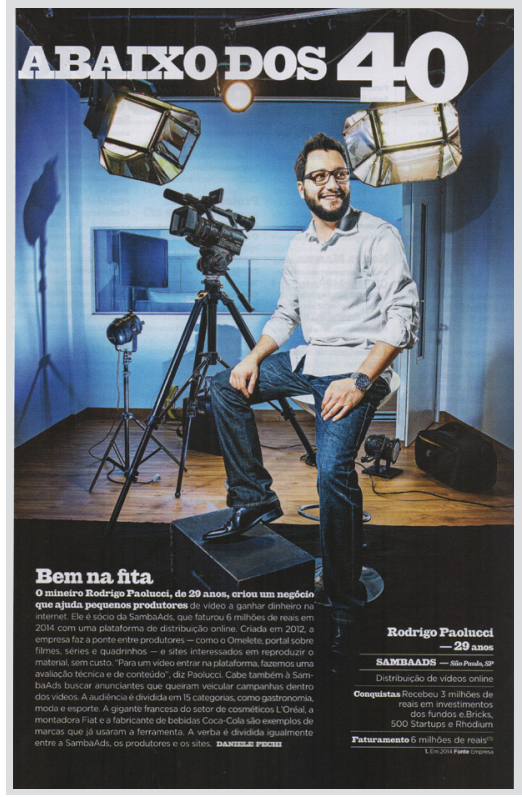

destacabilidade, ou sobreasseveração, um conjunto de propriedades de certas frases que permite seu destacamento e circulação, muitas vezes fora do texto de origem/fonte. "Sem texto" indica o final de um processo, que vai da destacabilidade ao destacamento ou aforizações, acarretando maior ou menor alteração do original, desde pequenas supressões do enunciado até mudanças de locutor.

A destacabilidade é entendida como o ato de realçar um segmento, de abrir a possibilidade de uma sequência ser extraída/destacada do interior de um texto, desde que uma ou mais condições sejam preenchidas: enunciados curtos, constituídos o mais frequentemente de uma só frase; posicionados, em geral, no início ou no fim de um texto; com valor generalizante e organização interna forte etc. Já a aforização resulta de uma operação de destacamento e materializa-se no próprio enunciado destacado.

As reflexões acerca desses dois fenômenos encontram-se na oposição de dois tipos de enunciação que obedecem a dois regimes de naturezas distintas, um regime textualizante, que se materializa no encadeamento de enunciados no interior do quadro mais geral dos múltiplos gêneros de discurso, e um regime aforizante que escapa ao regime usual da oposição entre frase e texto. A frase é um constituinte de um texto, a aforização escapa à textualidade.

Por definição, a aforização é uma frase "sem texto". No nível mais imediato, isso significa que ela não é precedida ou seguida de outras frases com as quais está ligada por relações de coesão, de modo a formar uma totalidade textual ligada a um gênero do discurso. (MAINGUENEAU, 2014, p. 30)

Toda aforização, quando destacada de um texto, faz parte de uma lógica de discurso relatado em estilo direto. "As aspas desempenham, assim, com frequência, um papel crucial para atestar a existência efetiva da aforização." (MAINGUENEAU, 2014, p. 33). Na edição de abril (Fig. 2), o empreendedor Fabien Mendez, cujo sucesso advém de uma empresa que conecta motoboys que fazem entregas de pequenas encomendas, dá o seguinte depoimento: "Criei a Loggi logo depois que as novas regras começaram a valer." (referência às normas federais que passaram a regulamentar a atividade) "Foi um sufoco achar motoboys dentro da lei, mesmo oferecendo a eles $80 \%$ do valor da corrida." Mendez passou, então, a premiar os motoboys: "Dou 100 reais a quem indica alguém regularizado". As três frases enunciadas em estilo direto convergem para a construção do enunciado aforizado pela revista: Um motoboy indica o outro, procedimento largamente utilizado pela mídia contemporânea. 
A frase Garotos-prodígio está relacionada à temática da edição de maio (Fig. 3), centrada na história de dois amigos, Henrique Dubugras e Pedro Franceschi que, desde a infância, programavam softwares. "Aos 8 anos, Franceschi ensinava usuários a desbloquear o iPhone para ser usado em qualquer operadora [...]". Ainda adolescentes, ganharam, em 2012, US\$ 50.000 ao vencer um hackthon (maratona de programação em Miami, EUA) com um aplicativo de paquera semelhante ao Tinder. No ano seguinte, usaram o dinheiro daí proveniente para fundar a Pagar.me, empresa que faz a intermediação de pagamentos online nos moldes do PagSeguro e do PayPal. O relato, em primeira pessoa, procura provocar uma identificação enunciadores/coenunciadores, fazendo um nós assumir o texto, quer nas palavras de Dubugras, "Oferecemos tecnologia que esses serviços não possuem, como enviar um boleto ao cliente que tem o pagamento negado no cartão de crédito", quer nas de Franceschi, "Prevemos crescer mais de dez vezes neste ano". Tal procedimento destina-se a servir de lugar de inscrição de coenunciadores jovens, convidados a ser empreendedores bem sucedidos e, por que não, Garotos-prodígio? Sabe-se que a identidade dos autores exerce um papel essencial na atividade de aforização, daí a frase "sem texto" que dá título à matéria.

Já o microempreendedor Rodrigo Paolucci, edição de junho (Fig. 4), é sócio da SambaAds, empresa que disponibiliza uma plataforma de distribuição de vídeos online, fazendo a ponte entre pequenos produtores de vídeo, sites interessados em reproduzi-los, sem custos, e anunciantes que queiram veicular campanhas em tais vídeos. "Para um vídeo entrar na plataforma, fazemos uma avaliação técnica e de conteúdo", diz Paolucci, que se apresenta, por meio de sua fala, como o fiador da empresa, a SambaAds. Ambos ficam Bem na fita e conseguem "anunciantes-celebridade", como "a gigantesca francesa do setor de cosméticos L'Oréal, a montadora Fiat e a fabricante de bebidas Coca-cola".

Os três enunciados aforizados pela PME - Um motoboy indica o outro, Garotos-prodígio e Bem na fita - associados às fotos de jovens sorridentes (vestidos informalmente, de jeans, alguns deles de tênis, antítese dos executivos clássicos), todos eles integrados aos respectivos "locais" e instrumentos de trabalho, formam um grupo de aforizações, de frases "sem texto" que pretendem ser a síntese da seção Abaixo dos 40.

Esses enunciadores jovens, que impulsionam o desenvolvimento econômico, são constituídos por rapazes. O empreendedorismo feminino ainda é ambivalente, aparece em algumas das capas da revista, por exemplo, na edição de abril, mas é pouco explorado nesta seção, embora as mulheres brasileiras ocupem o $7^{\circ}$ lugar no ranking mundial entre as mais empreendedoras do mundo e sejam responsáveis por $38 \%$ do total de estabelecimentos empresariais do país segundo o GEM (2007). Tal silenciamento ocorre não apenas na revista, mas também na literatura e nas pesquisas em geral: "relativamente pouca atenção tem sido dada às atividades de conexão e desenvolvimento de redes de mulheres empreendedoras" (HAMPTON; COOPER; MCGOWAN, 2009, p. 193).

Silenciam-se também os custos operacionais da empresa, valores de capital de giro, eventuais dívidas ou dificuldades enfrentadas pelo empreendedor. São silenciadas, ainda, as barreiras e dificuldades por que passam a grande parte (senão todos) os empreendedores, em diferentes fases do negócio. Quando suas vicissitudes aparecem, a despeito de todos os obstáculos, sonham, investem, trabalham, geram empregos e fazem o Brasil avançar (Carta ao Leitor, edição de junho/2015).

\section{Qual é, então, o ethos do jovem empreendedor construído pela revista PME Exame?}

A PME, por sua própria enunciação, visa a integrar enunciadores e coenunciadores em um mesmo mundo ético, o dos empreendedores competentes, brilhantes, bem sucedidos, algumas vezes verdadeiros prodígios, atualizados, corajosos, inovadores e agentes de mudança da sociedade; e o faz em um tom didático, confiante e seguro. Por seu modo de dizer e de mostrar, o discurso da PME Exame, tal qual outras do mesmo segmento, como a Vida Executiva, apresenta-se como uma instância reguladora e define um certo ideal de circular, conviver e se movimentar que associa as ideias que promove a uma maneira de habitar determinado espaço social, o mundo do empreendedorismo (SOUZA-E-SILVA, 2008, p. 275).

Enunciadores e coenunciadores compartilham da mobilidade, relatividade e individualismo característicos do empreendedor, sempre pronto a prover métodos inovadores no mercado de trabalho. Trata-se aqui do processo de incorporação que evoca "imbricação radical do discurso e do seu modo de enunciação" (MAINGUENEAU, 2008b, p. 93). A PME Exame, apoiando-se em estereótipos validados, mantém, assim, uma ligação privilegiada com o ethos; busca persuadir, ao associar os valores que promove a uma nova maneira de habitar o mundo do trabalho. Empreender é um sonho, uma conquista e os jovens empreendedores são os responsáveis por impulsionar a máquina capitalista e prover novos bens de consumo. É sempre hora de mudança e a mudança é sempre positiva.

Olhando por outro viés, o sentido da mudança não é antecipável, as mudanças não se manifestam em uma única direção, 
é necessário aceitar a ideia de que não há modelos simples para pensar a mudança. Existe mudança, isto é indiscutível. Não aceitá-la é não ser contemporâneo de seu tempo. Mas é também necessário aceitar a ideia de que não se tem um modelo de interpretação única, que ninguém é expert no que tange à mudança, porque não se trata de apenas uma, mas de mudanças. (SCHWARTZ, 2010, p. 28)

É na esteira do pensamento de Schwartz que destacamos a importância de pensar a questão do empreendedorismo a partir da abordagem ergológica, um dos modos de reflexão referentes à produção de conhecimentos sobre as atividades humanas socializadas, especificamente do trabalho, com base no diálogo e/ou na confrontação entre os "saberes instituídos", conceitualizáveis, provenientes das prescrições, e os "saberes investidos", que correspondem ao grau de apropriação das dimensões históricas, singulares e coletivas de cada situação de trabalho e o "debate de valores" a que se vê convocado todo indivíduo em um meio de trabalho particular (SCHWARTZ, 2011).

A inter-relação entre saberes e deveres é também enunciada pelo autor sob a forma de conversa, agrupada em três proposições que caracterizam a atividade humana em geral e a de trabalho em particular (SCHWARTZ, 2010, p. 42-43): (i) a distância entre as normas, as prescrições e a atividade realizada é universal. Essa distância se explica em decorrência da variabilidade das situações de atividade de trabalho e também do que significa viver no trabalho para cada um. Qualquer que seja a situação, haverá sempre uma distância entre o que se pensa acerca do trabalho e a realidade desse trabalho. Os trabalhadores/as renormalizam permanentemente seus postos de trabalho; (ii) é impossível prever a distância entre as normas e a atividade realizada. Conhecê-la, ao menos em parte, implica ir a campo e estar atento à verbalização do trabalhador; (iii) finalmente, a terceira proposição traz a questão do "debate de normas" e do "debate de valores" na mais ínfima atividade de trabalho. Esses debates são, ao mesmo tempo, debates de valores consigo mesmo e de ordem social.

Tais princípios implicam outro: "não podemos julgar o valor das mudanças no trabalho sem nos inquietar do ponto de vista daquele que trabalha" (SCHWARTZ, 2010, p. 29).

\section{O que diz um jovem empreendedor}

Entrevista realizada por Rio Stella $(2015)^{2}$ com um empreendedor na faixa etária de trinta anos, graduado e pós-graduado em administração pública, com experiência anterior como funcionário de uma empresa tradicional, e que se tornou empreendedor há menos de dois anos, possibilitou o acesso à fala de alguém que ocupa um lugar social em determinada área, a do empreendedorismo; fala essa que permite uma escuta ancorada nas palavras de Durrive (2014) atrás do "trabalhar conforme", isto é, conforme aquilo que é prescrito, há sempre um "trabalhar de outro modo."

Às prescrições da PME Exame, que apresentam modelos de empreender bem-sucedidos, opõe-se outro discurso que aponta para a complexidade da atividade de trabalho3: "Parece tudo lindo né... [nas revistas de negócios] (...) e é justamente o contrário... a chance de eu ficar rico é muito menor do que se eu trabalhar num banco de investimento".

$\mathrm{O}$ enunciador desse discurso é fundador de uma empresa, uma plataforma eletrônica, que funciona em modelo de coworking ${ }^{4}$, voltada para investimentos. Ao contrário do motoboy e dos garotos-prodígio, este empreendedor conta, além dele próprio, com três funcionários e um estagiário. E também ao contrário dos empreendedores da seção Abaixo dos 40, sua fala mostra as dificuldades do cotidiano, de chamar a si a responsabilidade pelo empreendimento: “(...) empreender de forma geral é muito difícil né... e é uma posição muito sozinha no fim (...) tem coisas que não adianta compartilhar... que é o meu papel decidir.. então eu acho que esse é o custo".

$\mathrm{O}$ apelo à iniciativa e à responsabilidade implicam "debate de normas", aquelas já vivenciadas em outras empresas em que o empreendedor trabalhou anteriormente - "tinha muitas coisas que me incomodavam (...) eu senti de não ter tanto feedback... não ter tanto acompanhamento" - e as novas que se apresentam no novo cotidiano:

\footnotetext{
"eu fico refletindo toda noite se eu não contratei muita gente (...) tem que realmente ser indispensável aquele gasto... isso eu fui aprendendo com o tempo (...) às vezes tem que arriscar ... arrisco... e se não der certo eu volto atrás... a gente fez isso".
}

Os "debates de normas" trazem também a questão dos "debates de valores" na atividade de trabalho, obrigação feita a cada trabalhador/a de repensar, no seu íntimo, suas escolhas na vida e no trabalho. Obrigação feita de escolhas, que implicam que cada um se situe, de uma maneira ou de outra, em um mundo de valores (SCHWARTZ, 2010 p. 27):

\footnotetext{
2 Dessa entrevista, estruturada em oito verbalizações, extraímos apenas alguns trechos. Os agrupamentos das falas, e comentários dela decorrentes, estão calcados na proposta deste artigo.

3 Os trechos em itálico indicam a fala do empreendedor.

4 As empresas que adotam esse modelo não têm escritório próprio. A equipe trabalha em uma mesa de um escritório compartilhado por outras empresas.
} 
"o meu trabalho dentre todos é o que menos tem uma rotininha uma disciplina (...) o meu dia a dia é um exercício constante de priorização (...) disciplina organização... então essas duas coisas casam... prioridade e trabalhar disciplina num ambiente caótico como é... eu acho o meu pelo menos de empreendedor de microempresa de startup... é um dos grandes desafios".

As diversas falas do empreendedor deixam ver as renormalizações, as múltiplas "dramáticas" da atividade. Falar da dimensão "dramática" não significa que cada agir seja semeado de dramas, mas sim que nada pode ser mecânico. Essas "dramáticas" são fonte de eficácia, mas têm um preço para as pessoas e os grupos e são inseparáveis de certos valores de vida e de saúde (SCHWARTZ, 2011, p. 133-134).

Esse contingente de microdramáticas é apagado/ ocultado se nos restringirmos apenas à análise da imagem do jovem empreendedor construída pela revista $P M E$ Exame.

\section{Considerações finais}

Se postularmos, ainda que provisoriamente, que os discursos sobre o trabalho são submetidos a uma lógica de campo onde se confrontam diversos posicionamentos, podemos dizer que os enunciados constituídos pelos discursos que circulam na revista $P M E$ Exame e por aqueles consubstanciados na fala de um jovem empreendedor sobre seu trabalho constroem identidades enunciativas que estão em relação de concorrência em sentido amplo, isto é, sua delimitação recíproca não passa por um confronto aberto.

\section{Referências}

COSTA, Alessandra Mello da; BARROS, Denise Franca; CARVALHO, José Luiz Felicio. A Dimensão Histórica dos Discursos acerca do Empreendedor e do Empreendedorismo. Revista de Administração Contemporânea, Curitiba, v. 15, n. 2, p. 179-197, mar./abr. 2011.

COSTA, Alessandra Mello da; BARROS, Denise Franca; MARTINS, Paulo Emílio Matos. A alavanca que move o mundo: o discurso da mídia de negócios sobre o capitalismo empreendedor. Cad. EBAPE.BR, Rio de Janeiro, v. 10, n. 2, p. 371-375, jun. 2012.

DORNELAS, José Carlos Assis. Empreendedorismo: transformando idéias em negócios. Rio de Janeiro: Elsevier/Campus, 2008.
DURRIVE, Louis. La démarche ergologique: pour un dialogue entre normes et renormalisations. Deuxième Congrès de la Société Internationale d'Ergologie. "Produire des normes et intervenir dans la vie des autres: savoirs et démocratie en travail”. Sierre, Suisse. 2014. Disponível em: <http://www. ergologia.org/uploads/1/1/4/6/11469955/expos_sierre_ldurrive. pdf $>$. Acesso em: 03 ago. 2014.

GEM. Empreendedorismo no Brasil: 2013. Simara Maria de Souza Silveira Greco (Coord.). Curitiba: IBQP, 2013.

GEM. Report on women and entrepreneurship. Babson Park, MA/US; London, UK: Babson: Author, 2007.

HAMPTON, Alison; COOPER, Sarah; McGOWAN, Pauric. Female entrepreneurial networks and networking activity in technology-based ventures: an exploratory study. International Business Study Journal, v. 27, n. 2, p. 193-214, 2009.

MAINGUENEAU, Dominique. Frases sem texto. Tradução Sírio Possenti et al. São Paulo: Parábola. 2014. [Les phrases sans texte, Paris: Armand Colin, 2012].

MAINGUENEAU, Dominique. Análise de textos de comunicação. Tradução M. Cecília de Souza e Silva e Décio Rocha. 6. ed. ampliada. São Paulo: Cortez. 2013. [Analyser les textes de communication. Paris: Dunod, 1998; 2007].

MAINGUENEAU, Dominique. A propósito do ethos. In: MOTTA, Ana Raquel; SALGADO, Luciana (Org.). Ethos discursivo. São Paulo: Contexto, 2008a. p. 11-29.

MAINGUENEAU, Dominique. Gênese dos discursos. Tradução Sírio Possenti. São Paulo: Parábola, 2008b. [Genèses du discours. Paris: Pierre Mardaga, 1984].

RIO STELLA, Vivian Cristina. As dramáticas do uso de si de um jovem empreendedor. Ergologia, n. 13, 2015 (prelo).

SCHWARTZ, Yves. Manifesto por um ergoengajamento. In: BENDASSOLLI, Pedro F.; SOBOLL, Lis. A. P. (Org.). Clínicas do trabalho: novas perspectivas para compreensão do trabalho na atualidade. São Paulo: Atlas, 2011. p. 132-166. [L'activités en dialogues: entretiens sur l'activité humaine II. Toulouse: Octarès, 2009].

SCHWARTZ, Yves. Trabalho e Ergologia; Reflexão em torno de um exemplo de trabalho operário. In: SCHWARTZ, Yves; DURRIVE, Louis (Org.). Trabalho e ergologia: conversas sobre atividade humana. 2. ed. revista e ampliada. Niterói: EDUFF, 2010. p. 25-36, 37-46. [Travail et ergologie: entretiens sur l'activité humaine. Toulouse: Octarès, 2003].

SOUZA-E-SILVA, C. P. Você sabe vender seu peixe? A construção do ethos da revista Vida Executiva. Investigações - Linguística e Teoria Literária, Pernambuco, v. 21, n. 2, p. 261-270, 2008. Disponível em: <www.ufpe.br/pgletras>.

Recebido: 30 de julho de 2015

Aprovado: 08 de setembro de 2015

Contato: cecilinh@uol.com.br vivian.rio@gmail.com 